Note: This is a pre-copy-editing, author-produced PDF of an article accepted for publication in Journal of substance misuse following peer review. The definitive publisher-authenticated version [McCann MH (1998) Drug services in Dublin: Selective or comprehensive strategies, Journal of substance misuse, 3(3), 150-155] is available online at

http://www.informaworld.com/smpp/content $\sim \mathrm{db}=\mathrm{all} \sim$ content=a907207182

\title{
Drug services in Dublin: Selective or comprehensive strategies
}

\section{Mary Helen McCann}

Published in Journal of substance misuse (now Journal of Substance Use), 1998, 3(3), $150-155$

Copyright: Taylor \& Francis

The development of community drug services in Dublin has long been a contentious issue between the health authorities and local communities. The conflict is analysed from a primary health care perspective, as defined by the World Health Organization. Interpretations of community involvement are discussed, with a case study from Ballymun, Dublin, described as an example of a more radical approach. Challenges to be faced in developing community participation are identified, and suggestions made for more comprehensive intersectoral collaboration to address the complexities in moving from a centralized, medical model to one based on comprehensive community care

\section{Introduction}

The development of local drug services in Dublin has long been a contentious issue between the Eastern Health Board (EHB), the statutory body with responsibility for health services in the Dublin area, and local communities. Opposition from the local communities to the establishment of such services has been analysed by the EHB as a 'not in my back yard' attitude, and has been attributed to the marginalized status of drug users internationally (EHB 1996).

This paper aims to question that analysis and review the difficulties that have arisen in the context of the complexities and challenges presented in moving from a medical 'micro' model to the 'macro' level, with greater community participation and intersectoral collaboration.

\section{Drug Problems in Dublin: a Historical Review}

\section{Overview}

Drug problems in Ireland were first discussed during the 1960s (Commission of Inquiry on Mental Illness 1966, Bushe 1968, Working Party on Drug Abuse 1971). By 1983, a statement on the final report of a Special Governmental Task Force on Drug Abuse (the full report was never published) described the people most vulnerable to drug abuse as those 'living in deprived urban communities' (Government Information Services 1983). Research studies confirmed this, revealing alarming rates of heroin use, particularly among already disadvantaged young people (Dean et al 1983, 1985, Power 1984).

Epidemiological evidence from treatment agencies (O’Higgins 1996), together with more general community reports and information tell us clearly that, far from the situation being relieved during the 1990s, problem drug use is a major issue for many of 
our communities (see reports from Rialto Development Association 1990, ICON 1994, Women's Action Group 1965, Co-operation North 1996, Community Response 1997).

These reports present a picture of communities struggling, in the midst of unemployment and poverty, to understand and cope with the devastation that problem drug use has brought. People are witnessing a second generation of young people dying from drug-related causes. The consequences are compounded by the sense of abandonment felt. The institutions of the State are seen as having ignored the warnings of previous decades.

\section{Service development}

The National Drug Treatment Service, based in Jervis Street Hospital, Dublin, was established in 1969 as a central response to individuals. Additional provision developed through voluntary agencies and self-help groups. The voluntary sector in Ireland has a long history, often with a foundation of religious involvement, in the provision of personal social services. The main sources of funding for the sector are charitable fundraising, funds from the European Union, and State funding. While the value of voluntary services has been stressed repeatedly, State funding of the sector is largely discretionary, lacking transparency and long-term commitment (National Economic and Social Forum 1995).

In line with similar shifts in England (Cartwright et al 1978), treatment for those affected moved from a centralized focus to a community focus when the EHB began to appoint addiction counsellors to work at community level in 1983. However, it was not until the early 1990s that this process took on a cohesive organizational rationale.

Influenced by the UK model of community drug teams, the Government Strategy to Drug Misuse (1991), recommended a similar model for drug treatment services in Ireland. The aspiration of community involvement contained in this strategy is reflected by the mission statement of the EHB addiction counselling service, which speaks of providing an accessible service 'optimising community participation in the evolution of appropriate services' (Burke 1994).

\section{Community action}

Communities in Dublin have organized in different ways in response to their drug problems.

In 1981, Ballymun, an area of high unemployment and social deprivation, set up its own response. The Youth Action Project aimed to address the demand for drugs in the south inner-city area of Dublin, people took action to evict drug pushers from their communities. (Similar action began again in 1996, with local people marching nightly in protest, and guarding their own streets to keep the supply of drugs out.)

Other groups include CAD (Community Awareness of Drugs), formed in 1983, and Community Response, formed in 1990. Despite the rhetoric of community participation, however, community groups in Dublin that have attempted to collaborate with the statutory authorities on the drugs issue have consistently experienced frustration and conflict. 


\section{Models of Community Involvement}

\section{A model from primary health care}

Perhaps the contribution that communities in Dublin can make to the development of drug services is best understood in the context of primary health care (PHC), which has community participation at the core of its effectiveness (WHO 1978).

Intended to increase the coverage, scope and quality of care in parts of the world where needs cannot be met by regular services because of special geographic and socioeconomic conditions (Quirke et al 1994), its seems to be a useful framework for considering the issues involved in moving drug services from centralized facilities to community care. Community involvement in its own health care is interpreted in a number of different ways (WHO 1986, McDonald 1993).

\section{The community as setting}

One common interpretation sees the community as a setting, with the originating agency having the resources and the power to make decisions and determine the timing, extent and terms of the service. Contact is made with the target population only when the service is about to be commenced, and location, staff and programmes have been decided upon.

This interpretation implies a positive alternative to residential care (NESC 1987), and could be said to be the dominant interpretation in the English model of the Community Drug Team, where services are provided in a locality instead of a central base. Set up as clinical units of various composition, these teams were given a task of consultancy to generic services in their area, with the aim of involving the professional carers in the care of drug users. However, results have been disappointing, with teams abandoning the consultancy role given by 1992, and the more disadvantaged groups still not being reached (Strang et al 1992)

This view of community involvement sees the relationship between the community and the health professionals in the conventional manner, where the worker is active, and the community passive, as are the patients (Jones \& Macdonald 1993). The State delivers, the community receives.

While clinical units at local level have a better chance of tailoring services to meet the needs of catchment areas (Strang et al 1992), this approach consumes a large slice of the budget, and has been rejected as a proper interpretation of community involvement in PHC (Banerji 1984, Macdonald 1993).

\section{The community as a resource}

A second model of community involvement involves equipping local people to implement projects which are largely determined by the outside sponsoring agency. In Ireland we have such an example of community participation in PHC, in the EHB's Community Mothers' Programme. This programme, initiated because the public health nurses could not meet the demands for services, recruited experienced mothers in disadvantaged areas to give support and encouragement to first-time parents in the rearing of their children, emphasizing health care, nutritional improvement and overall development. 
In PHC, the training of local people as care providers is not new (Werner 1981, Walt 1990). This model takes community involvement a step further and has many advantages. However, it is not without its limitations and dangers. These workers an become, instead of the change agents they have the potential to be, just 'another pair of hands' in the system (Walt 1990, Johnston 1993), resulting in 'system maintenance' rather than 'system transformation' (United Nations Research Institute Social Development 1979). This approach, much in line with the voluntary tradition in Ireland, is useful, but safe and secure. It is a model that is more readily approved than the more challenging approach of collective change. The concept of participation is not used as a yardstick for funding purposes, and the range of activities conducted in this way may be a substitute for a real policy (McCashin 1989).

\section{A more radical approach: community development}

Both of these approaches have their value and their successes. However, neither of them constitutes community participation as laid down by the World Health Organization (WHO) in 1978 and reinforced in 1987. PHC requires and promotes 'maximum community and individual self-reliance and participation in the planning, organisation, operation and control of primary health care, making fullest use of local, national and other available resources; and to this end develops through appropriate education the ability of communities to participate' (WHO 1978 .4, Article VII).

The approach is very similar to a community development approach, with its basic principles of participation, equity and intersectoral collaboration (Jones \& Macdonald 1993). It is an approach that encompasses a commitment to a holistic approach to health, recognizing the central importance of social support and social networks, and attempting to facilitate individual and collective action around common needs and concerns which are identified by the community itself, rather than being imposed from outside (Smithies \& Adams 1990).

WHO speaks of the essential ingredient of massive public involvement, 'not just in the support and operation of health services, but more importantly in the determination of health priorities and the allocation of scarce health resources.' (WHO 1991, p.3, emphasis added). This is a more radical approach.

While Community Development for Health appears under many forms and guises (Beattie 1986, Gabe 1994), participation has been defined as having essential elements:

- Participation must be active; more receiving of services does not constitute participation

- Participation involves choice

- Choice must have the possibility of being effective (Rifkin et al 1988).

\section{A Case Study: Ballymun Youth Action Project}

Ballumun, situated on the northside of Dublin, near Dublin Airport, is a high-rise housing estate built in the late 1960s in response to a housing crisis in the city. The modern blocks of flats, intended to show a 'new Ireland', became instead the most disadvantaged area of the State (EHB 1984). 
In a climate of seeping poverty, and increased social isolation (SUSS Centre 1987), local parents approached the EHB community worker to help them find a way to respond to the drug abuse that was creeping into the community and which had led to the deaths of three young people towards the end of 1980.

Early assessment of local drug patterns identified drug abuse as becoming part and parcel of community life, ranging from children abusing cough bottles and solvents to teenagers abusing barbiturates and tranquillizer drugs with alcohol, and to the abuse of injectable opiates by hard-core addicts. The abuse was also seen as part of the problem.

In the Youth Action Project, from its earliest days, the problem was seen as both personal and systemic. The interaction of the community could be constructive or destructive (McCann 1991).

The committee was concerned with service provision. At the time of its founding, there were no drug services in the area. Young people were dying, and families were being left to cope on their own. From the beginning, the project adopted a policy of training local people, seeing the passing on of skills as of major importance. Therefore, it has been concerned not only with what is provided but how it is provided and who provides it. By the end of 1986, the Youth Action Project was offering a comprehensive support system, being seen as a very worthwhile and essential service in the area (Youth Action Project 1986).

In 1997 there is a workforce of 13 people involved in client work, education work, development work, training, liaison and administration. Eight members of the workforce are local people. In developing this expertise, the Youth Action Project has consistently challenged the role given to it by statutory authorities (Irish Times 1985, McCann 1991 p.62, Judge 1992 p.32).

Through this work its has been shown that local people can be, as in the Community Mothers' Programme and in programmes in New Zealand (Dulwich Centre 1990) and Los Angeles (Breslow \& Tai-Scale 1996), very effective in reaching those not usually engaged in services and in making programmes culturally appropriate.

Internal leadership, identified as the main criterion for successful community responses in the USA by Wynne (1973), is developed and use is made of internal and external resources.

\section{Ireland's first community addiction studies training centre}

Conscious that community involvement does not just happen, the Youth Action Project has established a community addiction studies training centre, the first of its kind in the country. Through this, it is developing the ability of communities and generic agents to participate. Staff already trained and experienced are involved in the centre, in passing on the skills they have acquired and in supervising two new full-time trainees form the local area.

A community addiction studies course, which runs regularly in the centre, consistently has twice as many applicants as available places, with enquiries from all over the city. Participants include people who have never studied before, people who reach Leaving Certificate level, and those who have participated in third level education. Also 
included are participants who themselves have been affected by problem drug use, either their own or by a family member.

Other disciplines requesting and receiving modules form this community initiative include probation officers, youth workers, teachers, residential care workers and home/school liaison coordinates.

This represents an innovative approach to the integration of the two key areas of expertise identified and developed by the Youth Action Project over the years: community work and drugs work. It provides a 'unique facility to meet the needs of the local community and professionals who encounter addiction and abuse in their work' (Rabbitte 1996 p.2). The Youth Action Project is pioneering a much-needed multidisciplinary response to a complex problem by integrating the concepts of community development in the design of effective responses to drug abuse.

To realize the full potential for change evident in these programmes, organizational structures and processes also need to reflect and value this work. By practising a community development approach, the dangers of merely adjusting people to poverty or other forms of injustice, or using local workers as 'just another pair of hands' (Walt 1990) are avoided.

The objectives in training local people are not only to equip them to work in service provision, but also, more importantly, to act as community consultants, as advocates, ensuring that any services that are developed by community, voluntary or statutory agencies are appropriate to local needs and are acceptable and accessible to the people (Dulwich Centre 1990). The Youth Action Project continually strives to move participation from the lower rungs of the ladder (Arnstein 1969) to higher levels where the community has more say and control over decisions and actions taken in Ballymun. Through a community development approach, the Youth Action Project brings the individual and the collective together, making the collective story as important as the individual ones (Starhawk 1987, Shapiro et al 1994).

In developing such an approach, the Youth Action Project was described as 'more than a service' by one client, during discussion on the occasion of the Project's tenth birthday conference in 1991.

\section{Discussion}

By 1991, WHO was saying that 'the changes and efforts required to realise community involvement have been underestimated, even misunderstood'. Despite the rhetoric in national and international documents, practice does not often correspond to aspirations (Madan 1987, McDonald 1993, Wallerstein 1993, Baum \& Sanders 1995). Indeed in drug abuse, practice has been shown to block community participation rather than promote it (McCann 1991, Cullen 1993). A community development approach is fraught with difficulties, and very challenging for the professionals involved (Werner 1981)

Plans drawn up by communities in Dublin incorporate the valuable elements of the first two models described here. However, they go further and look for more equal participation than these models offer. Management structures are criticized as inadequate for responding to the needs (ICO 1994, Rialto CDT 1996). 
Community development thinking is systems thinking. The systems approach emphasizes basic principles of organization. Of course in the treatment of problem drug users, there is an important role for the medical 'micro' approach, but in a systems view this has to be connected to structures which ensure the maximum benefit to individuals, families and the community. Rather than perceiving groups as casting doubt upon their knowledge and competence, and undermining them (Hunt 1990), outside professionals are challenged to develop the role to provide technical expertise and consultation on the problems and aid the community is seeking solutions (Quirke ct a1 1994, Breslow \& Tai-Scale 1990).

Structures that depend on hierarchy for cohesion are perhaps not in the best position to tackle effectively such a multifaceted entrenched problem. Through a $\mathrm{PCH}$ approach, new, more effective, structures can be put in place, which practice 'power with' rather than 'power over' (Starhawk 1987).

Good progress has been noted throughout the European region in improved health, except in the critical area of equity (WHO 1994). Equity has not been achieved in drug services in the UI<, in spite of expansion (Strang et a1 1996). Use of a community development approach, employing micro and macro techniques and strategies, would go some way towards the goal of equity in the drug misuse area, and ensure that a comprehensive continuum of care is developed for and with those in need, their families, and their communities.

In many countries, departments of health and community development do not work together or consult each other, in spite of the fact that workers often have similar agendas 2nd roles (Walt 1990). The strength lies in the two fields working together, avoiding selective strategies in favour of comprehensive ones.

Many of the basic principles for succcssfu 1 involvement outlined by Quirkc et a1 (1994) are present in our communities in their concern and efforts to protect their children from drug-related harm. This call be matched by the health board and other care providers: by accepting that communities are entitled to participate in service planning; by formally identifying workers who will provide support and technical backup, with approved role legitimacy and adequacy for development work' by accepting that shared care means shared control; and by treating communities as equals in the process of dialogue.

Previous claims of consensus and intersectoral collaboration in Irish policymaking have been 'superficial having been achieved and maintained by ignoring many real policy dilemmas ...' (Butler 1991 p. 230).

The effectiveness of structures at local and national levels depend on the debate going beyond superficial levels, on the real dilemmas being faced, and on the required analysis and study being undertaken.

In taking up these challenges, we will be congruent with community development and PHC as outlined by WHO, leading to more creativity and coordination $\mathrm{n}$ our activities. 


\section{References}

Arnstein S R I969 A ladder of citizen participation, Journal of the American Institute of Planners 3.5: 216-232

Baneji D 1984 Primary health care. Selective or comprehensive. World Health Forum 5 (4): 312--315

Baum F, \& Sanders D 1095 Can health promotion and primary health care achieve Health for All without a return to their more radical agenda? Health Promotion International 10 (2): 14L)-100

Beattie A 1986 Community development for health: from practice to theory? Radical Health Promotion 4 (summer); 12-18

Breslow L, Tai-Seale T 1996 An experience with health promotion in the inner city. American Journal of Health Promotion 10 (3): 185-188

Burke B 1994 Community addiction counselling - a social work perspective, Irish Social Worker $12(2)\{11-13$

Bushe a 1968 Drugs in Ireland, Series of 5 articles in The Irish Press, 16 September, National Library of Ireland

Butler S 1991 Drug problems and drug policies in Ireland: a quarter of a century reviewed. Administration 39 (3): 210-233

Cartwright A, Harwin J, Shaw S, Spratley T 1978 Responding to drinking problems. Croom Helm. London

Commission of Inquiry on Mental Illness 1966 Report, Stationery Office, Dublin

Community Response 1997 Dealing with the nightmare. Drug use and intervention strategies in south inner city Dublin, Community Response, Dublin

Co-operation North 1996 Report of drugs seminar held in the Ormond Hotel

Cullen K 1993 Community \& drugs - a case study in community conflict in an inner city community in Dublin, M. Litt. Thesis, Trinity College, Dublin

Dean G, Bradshaw J, Lavelle P 1983 Drug misuse in Ireland, 1982-1983. Medico-Social Research Board, Dublin

Dean G, Kelly M, O'Hare A, Kelly G, O'Connor A 1985 The opiate epidemic in Dublin 1979-1983. Irish Medical Journal 78 (4): 107-110

Dulwich Centre 1990 Newsletter no. 1, Social justice and family therapy, Dulwich Centre Publications, Auckland

Eastern Health Board 1984 Report of the Special Committee on Ballymun, EHB, Dublin

Gabe J 1994 Promoting benzodiazepine withdrawal, Addiction 89; 1497-1504

Government Information Services 1983 Government statement on the report of the special task force on drug abuse, 20 September

Government Strategy to Prevent Drug Misuse 1991 Stationery Office, Dublin, May

Hunt S 1990 Building alliances, professional and political issues in community participation. Health Promotion International 5 (3) 179-185

Inner City Organisations Network 1994 Grasping the future. Area action plan for Dublin's north-east inner city, ICON, Dublin

Irish Times 1985 Letter to the editor, 4 February

Johnston R 1993 Learning to work with people, An experience of health workers in Ireland, Community Development Journal 28 (3); 252-257

Jones J, Macdonald J 1993 Introduction: who controls health care? Community Development Journal 28 (3); 199-205

Judge J 1992 Humanistic psychology 'community style' Youth Action Project Annual Report, p.32-34 
McCann M E 1991 Ten years on, Ballymun Youth Action Project, Dublin

McCashin T 1989 Local communities and social policy, Community work in Ireland, Combat Poverty Agency, Dublin, p.81-84

Macdonald J J 1993 Primary health care: medicine in its place, Earthscan, London

McDonald A 1993 Partnership in health care, MSc dissertation, Trinity College, Dublin

Madan T N 1987 Community involvement in health policy: socio-structural and dynamic aspects of health beliefs, Social Science and Medicine 25 (6); 615-620

National Economic and Social Council 1987 Community care services: an overview, NESC, Dublin

National Economic and Social forum 1995 Quality Delivery of Social Services, Forum report no.6, February, NESC, Dublin

O’Higgins K 1996 Treated drug misuse in Greater Dublin, Review of five years 19901994, Health Research Board, Dublin

Power B 1984 Heroin use in Dun Laoghaire borough area 1983-84, Medico-Social Research Board, Dublin

Quirke B, Sinclair H, Kevany J 1994 Community participation in primary health care, Administration $42(20 ; 170-182$

Rabbitte P 1996 Speech on the occasion of presentation of certificates in Ballymun, 27 October

Rialto Community Drug Team (CDT) 1996 Policy discussion document

Rialto Development Association 1990 Survey Report

Ritkin S B, Muller F, Bichmann W 1988 Primary health care: on measuring participation, Social Science and Medicine 26 (9); 931-940

Shapiro M, Cartwright C, Macdonald S 1994 Community development in primary health care, Community Development Journal 29 (3); 222-231

Smithies J, Adams L 1990 Community participation in health promotion, Health Education Authority, London

Starhawk 1987 Truth or dare, Harper \& Row, London

Strang J, Smith M, Spurrell S 1992 The community drug team, The practical business of treatment - 18., British Journal of Addictions 87 169-178

Strang J, Gossop M, Powis B, Griffiths P 1996 The better-travelled treatment tourist, Service overlap among heroin and cocaine users, Druglink May/June: 10-13

SUSS Centre 1987 A block of facts, Ballymun community twenty one years one, SUSS Centre, Dublin

United Nations Research Institute for Social Development 1979, SUNRISD, 4

Wellerstein N 1993 Empowerment and health: the theory and practice of community change. Community Development Journal 28 (3)

Walt G 1990 The community health worker in national programme - just another pair of hands, Open University Press, Milton Keynes

Werner D 1981 The village health worker; lackey or liberator? World Health Forum 2 (1); 46-68

Women's Action Group 1995 Health and Quality of Life, WAG, Clondalkin, November

Working Party of Drug Abuse 1971 Report, Stationery Office, Dublin

World Health Organization 1978 Primary health care, a joint report by the DirectorGeneral of the World Health Organization and the Executive Director of the United Nation's Children's Fund, Declaration of Alma-Ata, WHO, Geneva

World Health Organization 1986 Patterns of community participation in primary health care, WHO, Geneva

World Health Organization 1987 Promotion of health: the Ottawa Conference, Ottawa charter for health promotion, World Health Forum 8; 114-115 
World Health Organization 1991 Community involvement in health development: challenging health services, Technical report series 809 , WHO, Geneva

World Health Organization 1994 Implementation of the global strategy for Health for All by the year 2000, Second evaluation, eighth report on the world health situation, vol. 5, European Region, WHO, Copenhagen

Wynne R D 1973 Effective co-ordination of drug abuse programs, a guide to community action, National Institute of Mental Health, Rockville, MD

Youth Action Project 1986 Annual Report, YAP, Dublin 